\title{
Abnormal energy regulation in early life: childhood gene expression may predict subsequent chronic mountain sickness Luis Huicho* ${ }^{* 1}$, Guoqiang Xing ${ }^{\dagger 2}$, Clifford Qualls ${ }^{3}$, María Rivera-Ch${ }^{4}$, Jorge L Gamboa ${ }^{5}$, Ajay Verma ${ }^{6}$ and Otto Appenzeller ${ }^{7}$
}

\begin{abstract}
Address: ${ }^{1}$ Departament of Paediatrics, Universidad Nacional Mayor de San Marcos, Universidad Peruana Cayetano Heredia, and Instituto de Salud del Niño, Lima, Peru, ${ }^{2}$ Department of Psychiatry, Uniformed Services University of the Health Sciences, Bethesda MD, USA, ${ }^{3}$ University of New Mexico, Department of Mathematics and Statistics and Clinical Research Center, University of New Mexico School of Medicine, Albuquerque NM 887131, USA, ${ }^{4}$ Departament of Biological and Physiological Sciences, Faculty of Sciences and Philosophy, High Altitude Research Institute, Universidad Peruana Cayetano Heredia, Lima, Peru, ${ }^{5}$ Department of Physiology, University of Kentucky, Lexington, Kentucky, USA, ${ }^{6}$ Department of Neurology, Uniformed Services University of the Health Sciences, Bethesda MD, USA and ${ }^{7}$ Department of Neurology, New Mexico Health Enhancement and Marathon Clinics Research Foundation, Albuquerque NM, USA
\end{abstract}

Email: Luis Huicho* - lhuicho@gmail.com; Guoqiang Xing - gxing99@yahoo.com; Clifford Qualls - clifford.qualls@gmail.com; María RiveraCh - mrivera@upch.edu.pe; Jorge L Gamboa - jlgamb3@email.uky.edu; Ajay Verma - ajay_verma@merck.com;

Otto Appenzeller - OttoArun12@aol.com

* Corresponding author †Equal contributors

Published: 27 October 2008

BMC Pediatrics 2008, 8:47 doi:10.1 I86/147|-2431-8-47
Received: II July 2008

Accepted: 27 October 2008

This article is available from: http://www.biomedcentral.com/I47/-243I/8/47

(c) 2008 Huicho et al; licensee BioMed Central Ltd.

This is an Open Access article distributed under the terms of the Creative Commons Attribution License (http://creativecommons.org/licenses/by/2.0), which permits unrestricted use, distribution, and reproduction in any medium, provided the original work is properly cited.

\begin{abstract}
Background: Life at altitude depends on adaptation to ambient hypoxia. In the Andes, susceptibility to chronic mountain sickness (CMS), a clinical condition that occurs to native highlanders or to sea level natives with prolonged residence at high altitude, remains poorly understood. We hypothesized that hypoxia-associated gene expression in children of men with CMS might identify markers that predict the development of CMS in adults. We assessed distinct patterns of gene expression of hypoxia-responsive genes in children of highland Andean men, with and without CMS.
\end{abstract}

Methods: We compared molecular signatures in children of highland (HA) men with CMS ( $n=$ $10)$, without CMS $(n=10)$ and in sea level $(S L)$ children $(n=20)$. Haemoglobin, haematocrit, and oxygen saturation were measured. Gene expression in white cells was assessed at HA and then, in the same subjects, within one hour of arrival at sea level.

Results: HA children showed higher expression levels of genes regulated by HIF (hypoxia inducible factor) and lower levels of those involved in glycolysis and in the tricarboxilic acid (TCA) cycle. Pyruvate dehydrogenase kinase I(PDKI) and HIF prolyl hydroxylase 3 (HPH3) mRNA expressions were lowest in children of CMS fathers at altitude. At sea level the pattern of gene expression in the 3 children's groups was indistinguishable.

Conclusion: The molecular signatures of children of CMS patients show impaired adaptation to hypoxia. At altitude children of CMS fathers had defective coupling between glycolysis and mitochondria TCA cycle, which may be a key mechanism/biomarker for adult CMS. Early biologic markers of disease susceptibility in Andeans might impact health services and social planning. 


\section{Background}

Human beings are considered hypoxia-sensitive; however, evidence for different adaptive strategies by various highland populations in coping with their hypoxic environment is abundant. Tibetans, for example, with a longer history of high altitude residence, seem better adapted than Andeans. This is implied by different steps in the oxygen transport cascade $[1,2]$. Thus, average resting ventilation and arterial oxygen saturation $\left(\mathrm{SaO}_{2}\right)$ are higher in Tibetans than in Aymaras and Quechuas of the Andes. In addition, Tibetans show lower frequency of intrauterine growth retardation, better neonatal oxygenation, lower pulmonary artery pressure and resistance, and lower frequency of chronic mountain sickness (CMS); a sudden loss of adaptation to their highland hypoxic abode appearing first in men in early midlife and in post-menopausal women $[3,4]$. In Ethiopians, $\mathrm{SaO}_{2}$ and haemoglobin values in high altitude residents similar to those of sea level subjects have also been reported [5]. These populations have been residents of the high altitude regions of the world for different lengths of time $[6,7]$. Natural selection may have equipped Tibetans and Ethiopians, who have resided at altitude for longer times, with molecular adaptations that have not, as yet, made their impact in the Andes. Moreover, not all subjects within a population of highlanders have similar susceptibilities to CMS, and a tendency to familial clustering of CMS in Andean populations has also been noted [8-10].

We hypothesized that, CMS patients and their children, who do not, as yet, have CMS by clinical criteria, may nevertheless, have suggestive molecular signatures that hint at an inability to cope with the metabolic demands of ambient hypoxia. This could be discernible in the impaired transformation of glycolysis-derived pyruvate into Acetyl CoA for efficient ATP production in mitochondrial TCA cycle and by the inadequate expression and activity of key enzymes controlling the coupling between glycolysis and TCA cycle in the face of hypoxia. Thus in adult CMS patients and their clinically normal children, the matching of cellular energy demands with efficient ATP production, in ambient hypoxia, might be impaired, eventually, leading to cellular energy "failure" in the patients[11]. This deficiency might already be discernable, to some extent, at a younger age.

Adaptation to chronic hypoxia in children such as physical growth, oxygen saturation, haemoglobin concentration, respiratory rate, and other cardiopulmonary modifications have been documented. [12-15]. To date no correlations of phenotypic changes with molecular signatures in children of Andean highlanders have been reported. Preliminary data from the highlands do suggest, however, that perinatal exposure to chronic hypoxia increases susceptibility to the later development of mala- daptation to life in chronic hypoxia such as CMS. [16]. We hypothesized that the molecular signatures of children might serve as biomarkers for the occurrence of CMS in adulthood.

We focused on oxygen-responsive genes and on those involved in glycolytic and mitochondrial metabolic pathways $[17,18]$.

\section{Methods \\ Design}

A cross-sectional study was performed in three groups; children of high altitude natives with CMS; children of high altitude controls, and sea level children without Andean ancestry. Absence of Andean ancestry was defined as absence of parents and grandparents native to high altitude. Ten children were recruited in each high altitude group and 20 in the sea level group. For each adult one child was studied. The children were matched by age and sex.

The protocol was approved by the Ethics Committee of Cayetano Heredia University, Lima, Peru. Before performing any procedure, a written informed consent was obtained from parents. Each child also gave separate written assent.

\section{Inclusion criteria}

Children native to and resident at Cerro de Pasco, aged 5 to 17 years, that did not drink regularly herbal infusions that might reduce red cell mass were included.

\section{Exclusion criteria}

Children with significant acute or chronic clinical conditions or those who had visited altitudes below $2000 \mathrm{~m}$ in the last 3 months were excluded.

\section{Study procedures}

High altitude children were studied in Cerro de Pasco first, and then transferred to Lima. Sea level natives were studied in Lima.

A clinical history, physical examination, weight and height measurements, and arterial oxygen saturation (pulse oximetry, $\mathrm{SaO}_{2}$ ) were obtained. Information on relevant current and past diseases, use of cytotoxic drugs or herbal infusions considered by natives as effective for reducing polycythaemia, and history of descent to altitudes below $2000 \mathrm{~m}$. were noted.

Blood samples were taken for haemoglobin and haematocrit determinations, and for RNA assays. Eight milliliters were drawn from children in Cerro and the same volume was taken in Lima. Haemoglobin was determined through spectrophotometry and haematrocrit through a 
standard capillary technique. At sea level, blood was taken from high altitude subjects within 1 hour after arrival to Lima for gene expression determination.

\section{Determination of gene expression through quantitative real-time PCR}

For quantitative real-time PCR determination, the total RNA of white blood cells was extracted through PAXgene Blood RNA kit (Qiagen, Germany) [11]. In brief, one microgram of total RNA was reverse transcribed into firststrand cDNA using the RETROscript reverse transcriptase kit and oligo dT primers (Ambion, TX), following the manufacturer's protocols. One microliter of cDNA from the reverse transcriptase reaction was used as the template for quantitative real-time PCR reaction with a final PCR reaction volume of $25 \mathrm{ml}$, with the 59 and 39 gene specific PCR primer concentrations at $100 \mathrm{nM}$ each. PCR primers were designed using Primer3 software (Whitehead Institute, MIT, Massachusetts, USA) according to the coding sequences of each gene. Quantification of mRNA expression was performed by triplicate using the SYBR Green SuperMix (BioRad, California, USA) and a 2-step PCR reaction procedure, performed on the MyiQ Single Color Real-Time PCR Detection System (BioRad, California, USA). After the initial denaturation at $95^{\circ} \mathrm{C}$ for 3 minutes, 45 cycles of primer annealing and elongation were conducted at $58^{\circ} \mathrm{C}$ for 45 seconds, followed by denaturation at $95^{\circ} \mathrm{C}$ for 10 seconds. Fluorescent emission data were captured, and mRNA levels were quantified using the threshold cycle value. To compensate for variations in input RNA amounts and efficiency of reverse transcription, data for each target gene mRNA of each sample were normalized by reference to the data obtained for the house keeping HPRT (GenBank accession number X62085) determined from the same sample. Each realtime PCR assay was repeated twice.

Definition and explanation of terms related to gene expression are detailed as an appendix (See additional file $1)$.

\section{Data analysis}

To assess the impact of specific genes on chronic mountain sickness-score (CMS-sc), using a sliding scale (continuous), we constructed an "impact table" for the combined (CMS \& Controls) Cerro de Pasco groups of fathers at altitude (Cerro de Pasco, $4338 \mathrm{~m}$.) and at sea level (Lima, 150 $\mathrm{m}$.). The impact table was constructed using CMS-sc of the fathers as a continuous variable and consists of the effect sizes (standardized beta) for each gene in univariate linear regression in the first columns, the effect sizes for each gene adjusting for the best univariate predictor (HPH3 at both altitudes) in the middle columns, and the residual effect size of HPH3 adjusting for each of the other genes in the final columns. The STB is the standardized estimate for the parameter estimate of an explanatory variable in the logistic regression model and is computed by multiplying the estimate by the sample standard deviation for the explanatory variable and dividing by $\pi / \sqrt{ } 3$. In addition to the comparison among high altitude groups, the Lima control subjects were compared to the high altitude groups, while in Lima.

Gene expression data were log transformed to obtain symmetric distributions for analysis and for graphical purposes. For comparing means of more than two groups at high altitude and at sea level, ANOVA test was run. The gene expression variables that best predicted the CMS classification of 10 Cerro de Pasco fathers with CMS and 10 Cerro de Pasco control-fathers were obtained by considering 1 and 2 variable models in stepwise and "all subsets" logistic regression, sensitivity and specificity using median cut scores, and the effect sizes (standardized beta) in univariate and bivariate logistic regressions at sea level (Lima) and at altitude (Cerro de Pasco, $4338 \mathrm{~m}$ ). The best two gene model using expressions at sea level (Lima) in the fathers was LDHA based on sensitivity $(90 \%)$ and specificity (100\%) and PDP2 based on effect size (standardized beta) in logistic regression [11]. Since lactate dehydrogenase A (LDHA) was not measured at high altitude (Cerro), PDK3 was used, based on having the highest correlation with LDHA at Lima. The "niche" scatterplots show the two predictor genes selected as best at each altitude for the children.

All the analyses were run using SAS 9.1 and SPSS 13.0.

\section{Results}

Children from all three groups were comparable in weight, height, blood pressure, respiratory rate, and heart rate. Sea level children were somewhat younger than those from high altitude (Table 1). As expected, haemoglobin and haematocrit were significantly lower and $\mathrm{SaO}_{2}$ significantly higher in sea level children than in any of the high altitude groups (Table 1).

\section{HIF-regulated genes}

The impact table shows the predicting power of specific hypoxia-related genes on CMS in the fathers of Andean children (Table 2). Note that the genes were assayed in children, whereas the CMS scores were those of their fathers.

In univariate linear regression model, HPH3 (assayed in the children) was found to be the most significant predictor of CMS-sc in the fathers (Table 2, in bold font). Adjusting for HPH3 eliminates the impact of the other genes on the CMS-sc (columns "adjusted for HPH3"). However, adjusting HPH3 for each of the remaining genes, assayed here, strengthens the impact of HPH3 (columns "adjusted 
Table I: Demographic and clinical characteristics of children by groups

\begin{tabular}{lccc}
\hline & SL children & HA control children & CMS children \\
\hline Age (yrs) & $9.91(3.15)^{*}$ & $13.05(3.35)$ & $12.24(2.65)$ \\
Weight (kg) & $38.45(13.53)$ & $37.98(10.49)$ & $35.87(10.67)$ \\
Height (cm) & $132.45(20.41)$ & $140.60(14.37)$ & $140.70(17.46)$ \\
Hb(g/dL) & $12.74(0.84)^{* *}$ & $15.44(1.02)$ & $15.69(1.42)$ \\
Hct (\%) & $38.73(2.52)^{* *}$ & $47.08(3.09)$ & $47.45(4.29)$ \\
SaO & $98.95(2.11)^{*}$ & $94.75(5.56)$ & $94.30(6.34)$ \\
HR (beats/min) & $74.30(12.06)$ & $69.35(10.82)$ & $75.05(18.22)$ \\
RR (resp/min) & $23.50(5.46)$ & $22.50(4.35)$ & $23.80(5.06)$ \\
SBP (mmHg) & $95.00(13.95)$ & $97.00(8.01)$ & $92.00(8.94)$ \\
DBP (mmHg) & $57.75(8.66)$ & $58.00(8.94)$ & $57.50(7.69)$ \\
\hline
\end{tabular}

SL: sea level; HA: high altitude; CMS: children from subjects affected by CMS. Difference between groups (ANOVA): $*_{p}<0.05$; $*^{*} p<0.00$ I

HPH3"). This supports the importance of HPH3 as measured in the children, in predicting CMS-sc of their fathers at altitude. However, in Lima (normoxia) in the univariate linear regression model, LDHA was found to be the most significant predictor of CMS-scores of the fathers. But, because there were no significant differences in expression levels in the 3 children's groups at Lima, the impact of LDHA was weakened (columns "adjusted LDHA") in normoxia.

Hypoxia Inducible Factor 3 is a prolyl hydroxylase (HPH), an enzyme that allows oxygen tension to control HIFalpha protein levels; LDHA is involved in "buffering" pyruvate by reversibly converting to lactate. It favors formation of lactate, when pyruvate builds up too quickly or when there is a block in pyruvate metabolism due to pyruvate dehydrogenase inhibition or lack of sufficient oxygen.

Genes directly regulated by HIF showed lower expression levels (EPO, HPH1, HIF-1 alpha, HIF-1 beta, HIF-2 alpha, HIF-3 alpha, HPH1, HPH3, and EPOR) in the sea level children group than in both of the high altitude groups when their samples were collected at high altitude. By contrast, all genes were expressed at similar levels for all 3 groups at sea level, except for EPOR, which was higher in HA controls (Table 3). Gene expression did not differ significantly between HA controls and HA children of fathers with CMS while they were studied at high altitude (Table 3).

\section{Genes involved in glycolysis and in the Krebs cycle}

Gene expression of PDK1, PDK2, PDK3, PDK4, PDP1, PDP2, PDHE1A1, and GADPH was higher in sea level children than in their high altitude counterparts when they were examined in their native high altitude environment (Table 4). Whereas, at sea level, children of fathers with CMS showed similar gene expression levels to HA controls and sea level children (Table 4).

\section{Niche graphs}

The "niche" scatter plots illustrate the two gene expression levels that best predicted "CMS parenthood" in the children (HPH3 and PDK1). This expression was significantly lower at altitude than at sea level (Fig. 1). Moreover, the children of parents with CMS had even lower expression levels of these genes than HA control children; and they were clearly separated by the discriminator line constructed based on discrimination of the two groups by logistic regression (Fig. 1). The control SL children, at sea level in Lima, have still higher expression levels for HPH3 and PDK1 (Fig. 1). Immediately after descent to sea level, normoxia, all highland children had similar expression levels of HPH3 and PDK1 (Fig. 2).

\section{Discussion}

Chronic mountain sickness causes enormous social problems in the high Andes such as early death of bread winners in usually large families and excessive burdens on already meager health services in the highlands [19]. To anticipate the occurrence of CMS and initiate preventive treatment may contribute to the well being of large numbers of villagers in the Andes and Altiplano. These social concerns have underscored our efforts to determine possible predictors of this disease.

We show, for the first time, using molecular signatures, defined as distinct patterns of gene expression, that children of fathers with CMS, who themselves show no signs of ill health, have distinguishing molecular signatures in their native highland environment (Fig. 1); a possible biomarker of the disease. By contrast, when hypoxia is removed by short sea level sojourn, the molecular signatures in these same highland children are indistinguishable from sea level children, (Fig. 2). We emphasize that no clinical evidence of CMS was detectable in the children, neither in their native highland village, nor during their short stay in Lima, Peru. The later occurrence of CMS, usually a disease of older men and post-menopausal women, 
Table 2: Impact table to show the predicting power of specific hypoxia-related genes on CMS (CMS-score $\geq 12)$ in the fathers of Andean children

\begin{tabular}{|c|c|c|c|c|c|c|c|c|}
\hline \multicolumn{3}{|l|}{ In Children } & \multicolumn{4}{|c|}{ Adjust for HPH3 } & \multicolumn{2}{|c|}{ Adjust HPH3 } \\
\hline At Cerro & STB & $\mathbf{P}$ & Cerro & STB & $\mathbf{P}$ & Cerro & STB & $\mathbf{P}$ \\
\hline log_EPO & -0.07 & 0.79 & log_EPO & -0.36 & 0.32 & log_HPH3 & 0.88 & 0.05 \\
\hline log_HPHI & 0.02 & 0.94 & log_HPHI & 0.06 & 0.84 & log_HPH3 & 0.75 & 0.07 \\
\hline $\log \_\mathrm{HPH} 2$ & 0.21 & 0.44 & $\log \_\mathrm{HPH} 2$ & 0.20 & 0.53 & log_HPH3 & 0.75 & 0.07 \\
\hline log_HPH3 & 0.74 & 0.07 & & & & & & \\
\hline log_VEGFC & -0.05 & 0.85 & log_VEGFC & -0.38 & 0.27 & log_HPH3 & 0.96 & 0.05 \\
\hline log_PDKI & -0.30 & 0.38 & log_PDKI & -2.69 & 0.18 & $\log \_\mathrm{HPH} 3$ & 2.82 & 0.08 \\
\hline log_PDPI & 0.16 & 0.55 & log_PDPI & -0.36 & 0.38 & log_HPH3 & 1.00 & 0.06 \\
\hline log_HIFIA & 0.67 & 0.07 & log_HIFIA & 0.51 & 0.19 & log_HPH3 & 0.61 & 0.17 \\
\hline log_HIFIB & -0.43 & 0.24 & log_HIFIB & -1.28 & 0.07 & log_HPH3 & 1.84 & 0.08 \\
\hline log_HIF2A & 0.61 & 0.08 & log_HIF2A & 0.78 & 0.13 & log_HPH3 & 1.00 & 0.11 \\
\hline $\log +H I F 3 A$ & 0.01 & 0.98 & $\log \_H I F 3 A$ & -0.17 & 0.62 & log_HPH3 & 0.77 & 0.06 \\
\hline log_POK2 & 0.02 & 0.94 & log_POK2 & -0.20 & 0.53 & log_HPH3 & 0.80 & 0.06 \\
\hline log_PDP2 & 0.06 & 0.83 & log_PDP2 & -0.18 & 0.58 & log_HPH3 & 0.80 & 0.06 \\
\hline log_PDK3 & -0.37 & 0.26 & log_PDK3 & -0.91 & 0.04 & log_HPH3 & 1.39 & 0.04 \\
\hline log_PDK4 & -0.21 & 0.45 & log_PDK4 & -0.20 & 0.51 & log_HPH3 & 0.73 & 0.07 \\
\hline log_PDHEIAI & -0.25 & 0.39 & log_PDHEIAI & -0.98 & 0.06 & log_HPH3 & 1.54 & 0.05 \\
\hline log_GADPH & -0.20 & 0.48 & log_GADPH & -1.01 & 0.08 & log_HPH3 & 1.62 & 0.05 \\
\hline log_EPOR & 0.24 & 0.40 & log_EPOR & -0.38 & 0.43 & log_HPH3 & 1.02 & 0.07 \\
\hline log_GLUTI & -0.15 & 0.59 & log_GLUTI & -0.53 & 0.15 & log_HPH3 & 1.05 & 0.05 \\
\hline log_LDHA & missing & & & & & & & \\
\hline \multirow[t]{2}{*}{ log_CATD } & missing & & & & & & & \\
\hline & & & & \multicolumn{3}{|c|}{ Adjust for LDHA } & \multicolumn{2}{|c|}{ Adjust LDHA } \\
\hline At Lima & & & Lima & STB & $\mathbf{P}$ & Lima & STB & $\mathbf{P}$ \\
\hline log_EPO & -0.13 & 0.61 & log_EPO & 0.13 & 0.70 & log_LDHA & -0.64 & 0.09 \\
\hline log_HPHI & 0.29 & 0.28 & log_HPHI & 0.45 & 0.20 & log_LDHA & -0.69 & 0.07 \\
\hline log_HPH2 & -0.38 & 0.18 & $\log \mathrm{HPH} 2$ & -0.20 & 0.51 & log_LDHA & -0.50 & 0.16 \\
\hline log_HPH3 & 0.12 & 0.67 & log_HPH3 & 0.40 & 0.34 & log_LDHA & -0.84 & 0.08 \\
\hline log_VEGFC & missing & & log_VEGFC & & & & & \\
\hline log_PDKI & $-0.27^{\circ}$ & 0.34 & log_PDKI & 0.17 & 0.68 & log_LDHA & -0.68 & 0.10 \\
\hline log_PDPI & -0.51 & 0.09 & log_PDPI & -0.28 & 0.44 & log_LDHA & -0.40 & 0.31 \\
\hline log_HIFIA & 0.18 & 0.50 & log_HIFIA & 0.48 & 0.20 & log_LDHA & -0.76 & 0.05 \\
\hline log_HIFIB & -0.26 & 0.32 & log_HIFIB & 0.11 & 0.76 & $\log L \mathrm{LDHA}$ & -0.65 & 0.12 \\
\hline log_HIF2A & -0.21 & 0.45 & log_HIF2A & 0.30 & 0.47 & log_LDHA & -0.69 & 0.07 \\
\hline log_HIF3A & 0.29 & 0.28 & $\log \_$HIF $3 A$ & 0.45 & 0.20 & $\log L \mathrm{LDHA}$ & -0.77 & 0.08 \\
\hline log_POK2 & -0.33 & 0.24 & log_POK2 & -0.16 & 0.64 & log_LDHA & -0.52 & 0.14 \\
\hline log_PDP2 & -0.41 & 0.17 & log_PDP2 & -0.01 & 0.99 & $\log L D H A$ & -0.57 & 0.25 \\
\hline log_PDK3 & -0.30 & 0.27 & $\log$ PDK 3 & 0.00 & 1.00 & log_LDHA & -0.58 & 0.14 \\
\hline log_PDK4 & -0.32 & 0.27 & log_PDK4 & -0.37 & 0.31 & log_LDHA & -0.61 & 0.09 \\
\hline log_PDHEIAI & -0.27 & 0.31 & log_PDHEIAI & 0.68 & 0.24 & log_LDHA & -1.20 & 0.07 \\
\hline log_GADPH & 0.12 & 0.67 & log_GADPH & 0.40 & 0.34 & log_LDHA & -0.84 & 0.08 \\
\hline log_EPOR & 0.33 & 0.25 & log_EPOR & 1.14 & 0.08 & log_LDHA & -1.21 & 0.03 \\
\hline log_GLUTI & missing & & & & & & & \\
\hline log_LDHA & -0.58 & 0.09 & & & & & & \\
\hline log_CATD & -0.46 & 0.13 & log_CATD & -0.09 & 0.85 & log_LDHA & -0.51 & 0.30 \\
\hline
\end{tabular}

may, therefore, be predictable during childhood, with important public health implications.

High altitude children had low expression of HPH3 and PDK1 in their native environment. Whereas HPH3 allows oxygen tension to control HIF-alpha protein levels; PDK1 is an enzyme involved in "aerobic glycolysis" (the Warburg effect). This enzyme supports a metabolic pattern seen in many hypoxia adapted tissues. Low expression of these two enzymes was a characteristic feature of children fathered by CMS patients when studied in their native ambient hypoxia (Fig. 1). But the removal of ambient hypoxia for 1 hour in Lima was sufficient to increase expression of these genes to levels comparable to those found in children of sea level fathers who have no altitude ancestry (Fig. 2). 
Table 3: Expression of genes regulated by HIF, at high altitude and at sea level

\begin{tabular}{|c|c|c|c|c|c|}
\hline & CMS children at HA & CMS children at SL & HA control at HA & HA controls at SL & SL children \\
\hline $\log$ EPO & $0.042(0.029)^{*}$ & $-1.979(0.189)$ & $0.040(0.025)$ & $-1.939(0.177)$ & $-1.793(0.502)$ \\
\hline log HIF-I alpha & $-6.059(0.565)^{*}$ & $-2.577(0.229)$ & $-6.647(0.453)$ & $-2.699(0.538)$ & $-2.49 \mid(0.657)$ \\
\hline log HIF-I beta & $-3.069(0.385)^{*}$ & $0.192(0.143)$ & $-2.865(0.200)$ & $0.258(0.155)$ & $0.191(0.252)$ \\
\hline log HIF-2 alpha & $-3.763(0.369)^{*}$ & $-1.183(0.172)$ & $-4.062(0.342)$ & $-1.086(0.376)$ & $-0.989(0.376)$ \\
\hline log HIF-3 alpha & $-5.430(0.432)^{*}$ & $-2.980(1.125)$ & $-5.422(0.225)$ & $-3.463(0.848)$ & $-2.963(0.844)$ \\
\hline log HPHI & $-0.245(2.880)^{*}$ & $-2.980(1.125)$ & $-0.088(2.885)$ & $-3.463(0.848)$ & $-2.963(0.844)$ \\
\hline $\log \mathrm{HPH} 2$ & $1.063(2.352)$ & $0.532(0.136)$ & $-0.149(2.357)$ & $0.613(0.124)$ & $0.447(0.207)$ \\
\hline $\log \mathrm{HPH} 3$ & $-5.545(0.673)^{*}$ & $-3.35 I(1.528)$ & $-6.166(0.499)$ & $-3.646(1.431)$ & $-2.773(1.701)$ \\
\hline $\log$ EPOr & $-2.981(0.340)^{*}$ & $0.127(0.159)$ & $-3.056(0.204)$ & $0.026(0.217)$ & $-0.029(0.189)$ \\
\hline
\end{tabular}

Difference between groups (ANOVA): ${ }^{*} \mathrm{p}<0.001$

How could HPH3 and PDK1 expression levels predict chronic mountain sickness later in life? Hypoxia, such as is inescapable in the highlands, leads to the formation of free radicals and oxidants [20]. These chemical species, by-products of mitochondrial metabolism, include the superoxides $\left(\mathrm{O}_{2}^{-}\right)$, peroxides $\left(\mathrm{H}_{2} \mathrm{O}_{2}\right)$ and hydroxyl radicals $\left(\mathrm{OH}^{-}\right)$are collectively designated as reactive oxygen species (ROS) [21]. However, these molecules are also crucial for the maintenance of homeostasis, especially in the face of hypoxia. The ROS abundantly formed during hypoxia modify proteins, allowing them to detect oxidants and maintain homeostasis, as has recently been shown for the guanosine $3^{\prime}, 5^{\prime}$-monophosphate cGMPdependent protein kinase PKG $1 \alpha$ isoform, a direct peroxide $\left(\mathrm{H}_{2} \mathrm{O}_{2}\right)$ sensor [22]. In addition, deficient peripheral PDK1 and HPH3 mRNA expression at altitude in children of CMS parents attests to a defective coupling between glycolysis and mitochondria TCA cycle, which may be a key mechanism/biomarker for adult CMS.

Recent studies on hypoxic cells identified critical adaptations that could prevent hypoxia-induced increases in ROS production and thus forestall ROS damage to cellular proteins. Amongst those adaptations is increased expression of PDK1 [17], and HPH3 may act in a similar fashion. Thus the childhood reduction of hypoxia-induced ROS accumulation at altitude, by appropriate up-regulation of PDK1 and HPH3, to levels we found in control children, might prevent time induced accumulation of ROS which ultimately may lead to the clinical development of the CMS syndrome in the children fathered by CMS patients.

The maintenance of homeostasis, the ability to maintain a steady state in the face of hypoxic stress, is fundamental to adaptation for life anywhere, including life in chronic hypoxia. Failure to upregulate genes that help maintain cellular homeostasis in hypoxia, as we found here, may place these children at an evolutionary disadvantage. Not surprisingly such disadvantage, if based on genetic differences, might be evident early in life.

Gene expression levels, as measured here, are the result of many factors that act on the DNA sequence. Epigenetic influences, a set of heritable DNA or protein changes not involving DNA mutations, are known to affect gene expression $[23,24]$. In addition, early environmental factors acting during embryonic, fetal, or early postnatal periods may also modify gene expression $[12,16,23]$.

We must acknowledge some methodological constraints. We studied our subjects in the field and thus strict laboratory procedures were usually unattainable. In addition, although larger numbers of subjects in each study group were desirable these could not be assembled because of time limitations at altitude for sea level researchers and

Table 4: Expression of genes involved in glycolisis, Krebs cycle, and related genes $\mathbf{-}$ at high altitude and at sea level

\begin{tabular}{lccrrr}
\hline & CMS children at HA & CMS children in Lima & HA control at HA & HA controls at SL & SL children \\
\hline log PDK-I & $-3.591(0.459)^{*}$ & $0.223(0.176)$ & $-3.419(0.149)$ & $0.299(0.178)$ & $0.253(0.243)$ \\
log PDK-2 & $-2.869(0.172)^{*}$ & $0.203(0.111)$ & $-2.858(0.167)$ & $0.281(0.173)$ & $0.171(0.240)$ \\
log PDK-3 & $-3.114(0.414)^{*}$ & $0.551(0.127)$ & $-2.918(0.206)$ & $0.620(0.147)$ & $0.446(0.222)$ \\
log PDK-4 & $-4.536(0.353)^{*}$ & $-0.564(0.310)$ & $-4.409(0.387)$ & $-0.402(0.331)$ & $-0.833(0.368)$ \\
log PDP-I & $-2.997(0.217)^{*}$ & $0.132(0.141)$ & $-3.019(0.237)$ & $0.238(0.113)$ & $0.030(0.214)$ \\
log PDP-2 & $-3.750(0.444)^{*}$ & $-0.678(0.201)$ & $-3.776(0.147)$ & $-0.576(0.091)$ & $-0.604(0.196)$ \\
log PDHEIAI & $-3.357(0.387)^{*}$ & $0.003(0.140)$ & $-3.193(0.308)$ & $0.070(0.154)$ & $0.001(0.206)$ \\
log GADPH & $-1.835(0.304)^{* *}$ & $-3.351(1.528)$ & $-1.744(0.183)$ & $-3.646(1.431)$ & $-2.773(1.701)$ \\
\hline
\end{tabular}

Difference between groups (ANOVA): ${ }^{*} \mathrm{p}<0.001$; ${ }^{* *} \mathrm{p}<0.005$ 


\section{Children CMS, CP Controls in Cerro and Lima Controls}
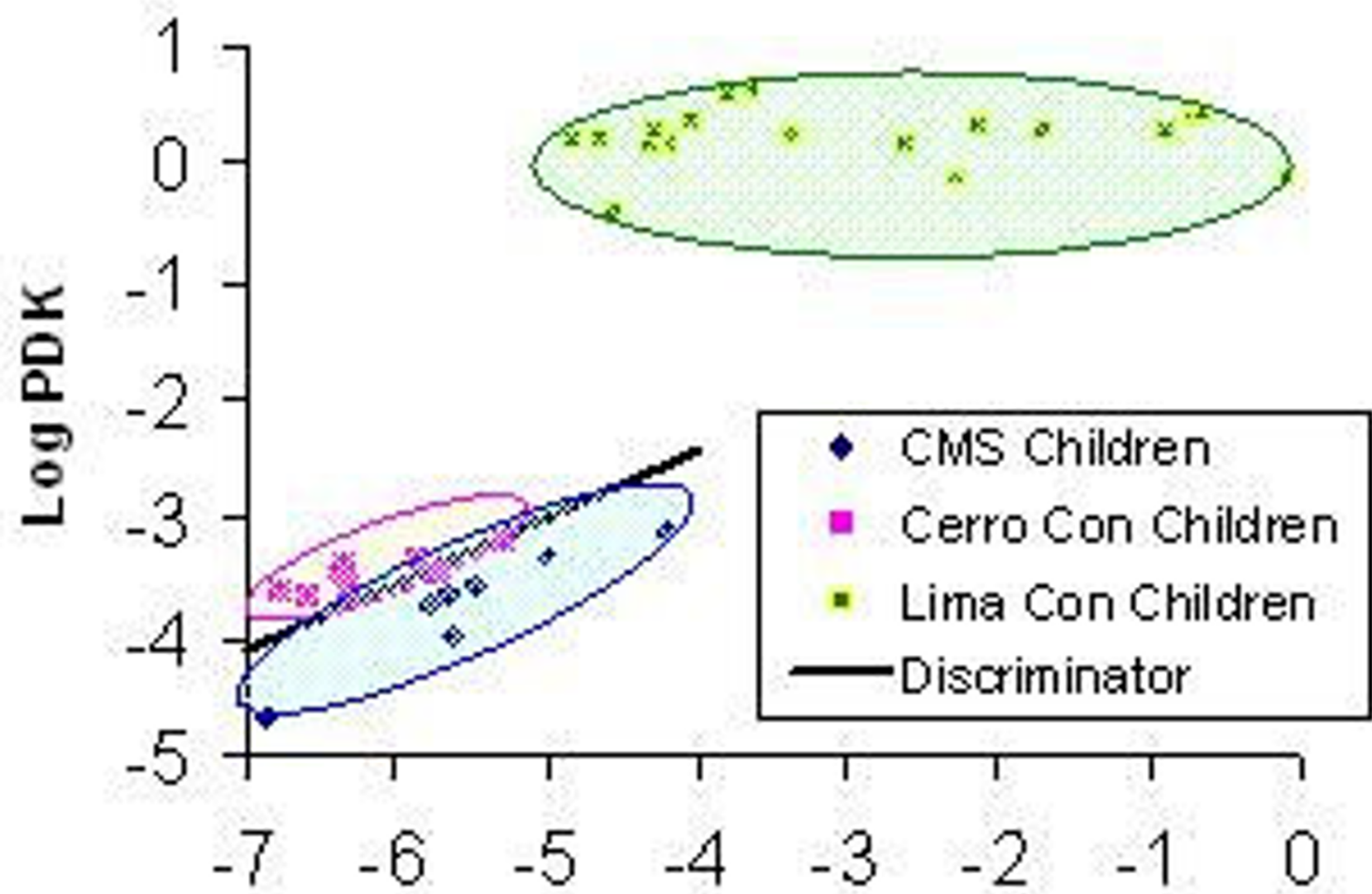

Log HPH3

Figure I

Niche (scatter) plots of gene expression levels in children that predict the CMS status of their fathers.

especially because molecular studies were combined with clinical evaluations in the same individuals. The research station of the Universidad Peruana Cayetano Heredia in Cerro de Pasco, Peru maintains a list of CMS patients and controls. We used this list to recruit our subjects in Peru. Because women are protected from CMS until the menopause, the list contains mainly men. Thus, the results of our earlier studies had unavoidable gender bias. Subsequently, the gender bias imposed on us previously constrained our selection. Therefore we used fathers only for CMS scoring purposes.
In previous field studies we found that exposure to 1 hour of normoxia at sea level, or 1 hour of hyperoxia at the resident altitude of highlanders [11] was sufficient to change gene expression in white cells [25], which predicated the short exposure times of highland children in Lima.

\section{Conclusion}

We designed this study to measure gene expression that may predict the later occurrence of CMS. Regardless of how such biomarkers may have been induced, by epigenetic influences, evolutionary pressures or failure to 


\section{Children CMS, CP Controls in Lima, and Lima Controls}

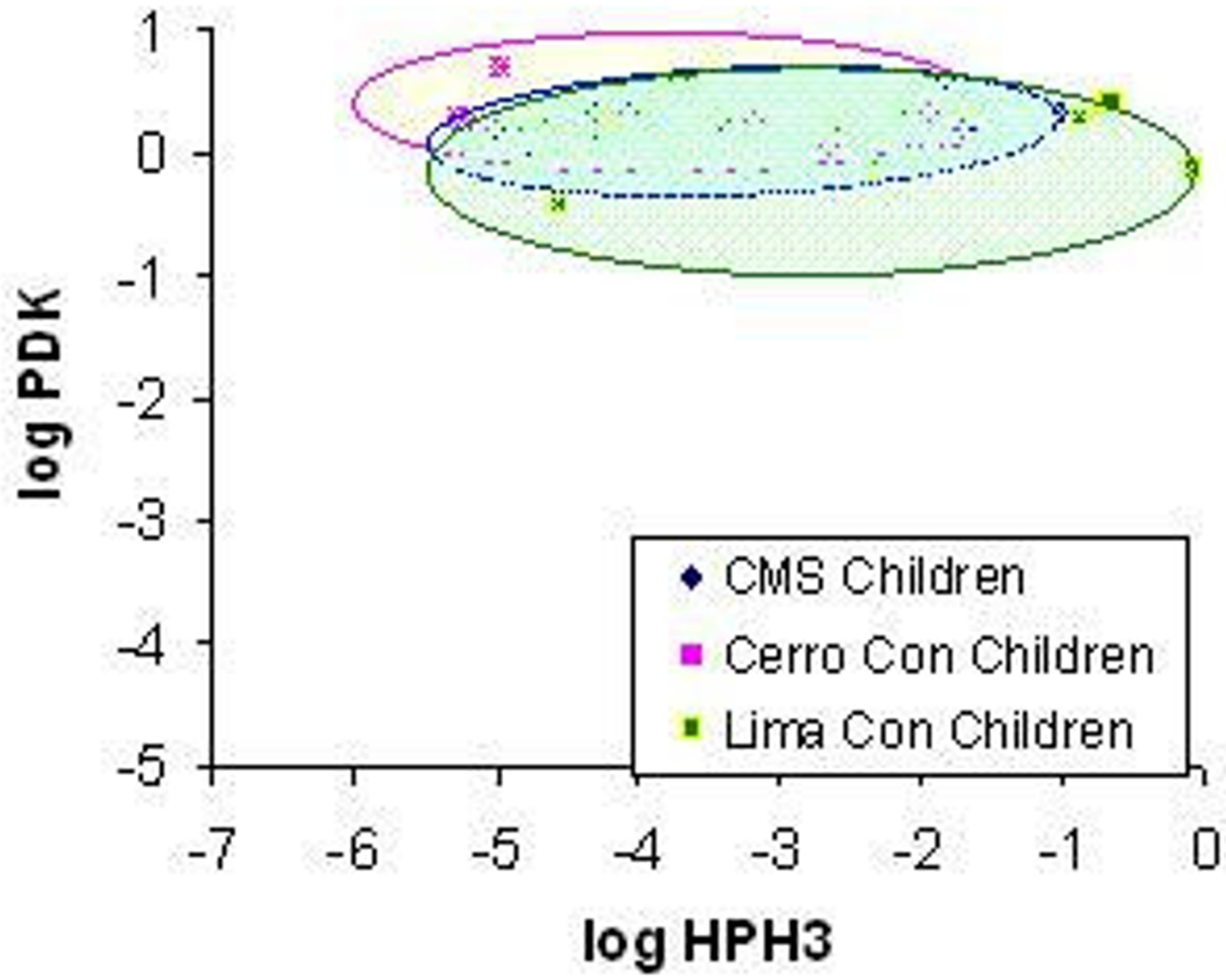

Figure 2

Niche (scatter) plots of gene expression levels in Lima in all 3 study groups. $\mathrm{CP}=\mathrm{Cerro}$ de $\mathrm{Pasco}, 4338 \mathrm{~m}$. Cerro $=$ Cerro de Pasco. CMS = chronic mountain sickness. Con $=$ controls.

respond to hypoxic stress, our findings point to an important role of particular genetic signatures in highland children for the later development of CMS. We anticipate that use of such biomarkers in planning for health promotion and social justice in the highlands of Peru might benefit the future of highland children in the Andes.

\section{Competing interests}

The authors declare that they have no competing interests.

\section{Authors' contributions}

$\mathrm{LH}, \mathrm{OA}$ and AV conceived and designed the experiments. GX performed gene expression analyses. CQ, OA and $\mathrm{LH}$ analyzed the data. AV, MRC, JG, and GX contributed with logistic and clinical support, and with selection of genes 
of interest. LH wrote the paper, and all other authors reviewed the manuscript and contributed with comments. All authors saw and approved the final version.

\section{Funding}

New Mexico Health Enhancement and Marathon Clinics Research Foundation Albuquerque NM USA. NIH Ro1 NS37814 to Ajay Verma.

\section{Role of the funding source}

The sponsors of the study had no role in the study design; collection, analysis, or interpretation of data; writing of the paper; or the decision to submit the paper for publication. The corresponding author had full access to all the data in the study and had final responsibility for the decision to submit for publication.

\section{Additional material}

\section{Additional file 1}

Supplementary file 1. Definition and explanation of terms related to gene expression.

Click here for file

[http://www.biomedcentral.com/content/supplementary/14712431-8-47-S1.doc]

\section{Acknowledgements}

Justino Panez helped in the recruitment of our subjects in Cerro de Pasco, Peru. Flor Raymundo performed blood sampling and laboratory analyses in Cerro de Pasco.

\section{References}

I. Moore LG: Human genetic adaptation to high altitude. High Alt Med Biol 200I, 2:257-79.

2. Beall CM: Tibetan and Andean patterns of adaptation to highaltitude hypoxia. Hum Biol 2000, 72:20I-28.

3. Niermeyer S, Yang P, Shanmina, Drolkar, Zhuang J, Moore LG: Arterial oxygen saturation in Tibetan and Han infants born in Lhasa, Tibet. N Engl J Med 1995, 333:1248-52.

4. Moore LG, Armaza F, Villena M, Vargas E: Comparative aspects of high-altitude adaptation in human populations. Adv Exp Med Biol 2000, 475:45-62.

5. Beall CM, Decker MJ, Brittenham GM, Kushner I, Gebremedhin A, Strohl KP: An Ethiopian pattern of human adaptation to highaltitude hypoxia. Proc Natl Acad Sci USA 2002, 99: I 72। 5-8.

6. Hochachka PW, Gunga HC, Kirsch K: Our ancestral physiological phenotype: an adaptation for hypoxia tolerance and for endurance performance? Proc Natl Acad Sci USA 1998, 95:1915-20.

7. Goebel T, Waters MR, O'Rourke DH: The late Pleistocene dispersal of modern humans in the Americas. Science 2008, 319:1497-1502.

8. Monge C: Chronic mountain sickness. Physiol Rev 1943, 23:166-84

9. Ergueta J, Spielvogel H, Cudkowicz L: Cardio-respiratory studies in chronic mountain sickness (Monge's syndrome). Respiration |97|, 28:485-517.

10. Beall CM, Brittenham GM, Strohl KP, Blangero J, Williams-Blangero S, Goldstein MC, Decker MJ, Vargas E, Villena M, Soria R, Alarcon AM, Gonzales C: Hemoglobin concentration of high-altitude Tibetans and Bolivian Aymara. Am J Phys Anthropol 1998, 106:385-400.
II. Xing G, Qualls C, Huicho L, Rivera-Ch M, Stobdan T, Slessarev M, Prisman E, Ito S, Wu H, Norboo A, Dolma D, Kunzang M, Norboo T, Gamboa JL, Claydon VE, Fisher J, Zenebe G, Gebremedhin A, Hainsworth R, Verma A, Appenzeller O: Adaptation and mal-adaptation to ambient hypoxia: Andean, Ethiopian and Himalayan patterns. PLoS ONE 2008, 3:e2342.

12. Huicho L: Postnatal cardiopulmonary adaptations to high altitude. Respir Physiol Neurobiol 2007, 158:190-203.

13. Frisancho AR: Developmental adaptation to high altitude hypoxia. Int J Biometeorol 1997, 21:135-46.

14. Rupert JL, Hochachka PW: The evidence for hereditary factors contributing to high altitude adaptation in Andean natives: a review. High Alt Med Biol 200I, 2:235-56.

15. Moore LG, Niermeyer S, Zamudio S: Human adaptation to high altitude: regional and life-cycle perspectives. Am J Phys Anthropol 1998:25-64.

16. Moore LG, Niermeyer S, Vargas E: Does chronic mountain sickness (CMS) have perinatal origins? Respir Physiol Neurobiol 2007, I58:180-9.

17. Semenza GL: Oxygen-dependent regulation of mitochondrial respiration by hypoxia-inducible factor I. Biochem J 2007, 405: I-9.

18. Papandreou I, Cairns RA, Fontana L, Lin Lim A, Denko NC: HIF-I mediates adaptation to hypoxia by actively downregulating mitochondrial oxygen consumption. Cell Metab 2006, 3:187-97.

19. Rivera-Ch M, León-Velarde F, Huicho L: Treatment of chronic mountain sickness: critical reappraisal of an old problem. Respir Physiol Neurobiol 2007, I 58:25I-65.

20. Bakonyi T, Radak Z: High altitude and free radicals. J Sports Science Med 2004, 3:64-9.

21. Hartzell HC: Cell biology. The stress of relaxation. Science 2007, 3 | 7:|33|-2.

22. Burgoyne JR, Madhani M, Cuello F, Charles RL, Brennan JP, Schröder $E$, Browning DD, Eaton P: Cysteine redox sensor in PKGla enables oxidant-induced activation. Science 2007, 3 17:1393-7.

23. Jaenisch R, Bird A: Epigenetic regulation of gene expression: how the genome integrates intrinsic and environmental signals. Nature Genet 2003:245-54.

24. Bird A: Perceptions of epigenetics. Nature 2007, 447:396-8.

25. Appenzeller O, Minko T, Qualls C, Pozharov V, Gamboa J, Gamboa A, Wang Y: Gene expression, autonomic function and chronic hypoxia:lessons from the Andes. Clin Auton Res 2006, 16:217-22.

\section{Pre-publication history}

The pre-publication history for this paper can be accessed here:

http://www.biomedcentral.com/1471-2431/8/47/prepub

Publish with Bio Med Central and every scientist can read your work free of charge

"BioMed Central will be the most significant development for disseminating the results of biomedical research in our lifetime. "

Sir Paul Nurse, Cancer Research UK

Your research papers will be:

- available free of charge to the entire biomedical community

- peer reviewed and published immediately upon acceptance

- cited in PubMed and archived on PubMed Central

- yours - you keep the copyright

BiolMedcentral 